\title{
PERDA DE MATÉRIA SECA EM GRÃOS DE MILHO SUBMETIDOS A SISTEMAS DE SECAGEM NATURAL E ARTIFICIAL
}

\author{
Diego de Lira Eiras ${ }^{1} \&$ Marco Antonio Martin Biagionni ${ }^{2}$
}

\begin{abstract}
RESUMO: A permanência de grãos na lavoura, após a maturação fisiológica, é causa importante de perdas, tanto sob aspecto quantitativo quanto qualitativo. Por cessar o aporte de substâncias assimiladas para os grãos, a partir da maturação fisiológica as reações de síntese são superadas pelas de respiração, responsáveis pela manutenção dos tecidos vivos dos grãos, e que ocorrem à custa de reservas acumuladas durante a formação do grão. Somam-se, ainda, perdas decorrentes de ataque de fungos e insetos e de condições climáticas desfavoráveis. O avanço tecnológico ocorrido nas últimas décadas, disponibilizando secadores de grãos com capacidades e eficiências variadas, tem propiciado a retirada antecipada do produto do campo, ainda úmido, reduzindo a sua deterioração. Por outro lado, o uso de sistemas artificiais de secagem pode representar um custo importante para o produtor. Assim, o presente trabalho teve por objetivo estudar o efeito de métodos de secagens natural e artificial sobre a perda de matéria seca em grãos de milho, para as condições de Botucatu-SP. O campo de produção do grão de milho foi instalado na Fazenda Experimental Lageado e os tratamentos experimentais foram conduzidos no Laboratório de Processamento de Produtos Agrícolas, pertencente ao Departamento de Engenharia Rural, onde se testou os sistemas de secagem, à sombra (testemunha), artificial com ar aquecido, artificial com ar não aquecido e secagem na planta. Foram realizadas as seguintes análises para monitoramento de qualidade: peso hectolítrico, peso de mil grãos, e massa de matéria seca dos grãos. Os resultados obtidos mostraram perda significativa na qualidade dos grãos secos na planta, tanto pela avaliação da perda de matéria seca como pela variação do peso dos grãos. A análise de peso hectolítrico indicou, porém, o pior desempenho para a secagem em alta temperatura. Utilizou-se técnicas para modelagem matemática que descrevam a perda de matéria seca, e ajustar o modelo matemático aos valores experimentais analisados. A partir dos dados experimentais obtidos durante a secagem na planta, foi possível ainda ajustar um modelo de regressão que estimasse a perda de matéria seca para a secagem de milho na lavoura, para as condições climáticas de Botucatu durante a safra 2011/2012.
\end{abstract}

PALAVRAS-CHAVE: Zea Mays, secagem de grãos, análise de qualidade, modelagem matemática.

\section{CORN GRAIN LOSS OF DRY MATTER UNDER NATURAL AND ARTIFICIAL DRYING SYSTEMS}

\begin{abstract}
The permanence of the corn grain in the field, after physiological maturity, is an important cause of crop losses, both in quantitative and qualitative aspect. By ceasing the supply of assimilated substances to grains, due to physiological maturity, the synthesis reactions are overcome by breathing, responsible for the maintenance of the living tissues of the grains, which occur at the expense of reserves accumulated during grain formation. In addition, there are losses from fungus and insects attack due to adverse weather conditions. Technological advances in recent decades, the develop of grain dryers with different capacities and efficiencies, has led to the early withdrawal of the product from the field, still damp, reducing spoilage. Moreover, the use of artificial drying systems can represent a significant cost to the producer. Thus, the present work aimed to study the effect of natural and artificial methods of drying on maize dry matter losses, for Botucatu, city of Sao Paulo state, Brazil. The cornfield production was conducted at the Experimental Farm "Lageado" and the experimental treatments were conducted in the Laboratory of Agricultural Products Processing, in the Department of Rural Engineering, where the drying systems were tested. The treatments were: shade (control), artificial with heated air, artificial unheated air and, drying attached to the plant. The following analyzes for quality monitoring were performed: weight test, thousand-grain weight test and, grain dry weight. The results showed significant loss in quality of drying beans attached to the plant, by assessing the dry matter loss and by the variation of the grain weight. The weight test showed that the worst performance was the artificial with heated air treatment. We used mathematical modeling techniques to describe the dry matter loss and adjusted the mathematical model to the experimental data analyzed. From the experimental data obtained during drying the grain attached to the plant, it was still possible to fit a regression model that estimates the loss of grain dry matter under the climate from Botucatu during the 2011/2012 harvest period.
\end{abstract}

KEYWORDS: corn, grain drying, quality analysis, mathematical modeling.

\footnotetext{
${ }^{1}$ Mestrado na Faculdade de Ciências Agronômicas de Botucatu. FCA/Unesp. Departamento de Engenharia Rural - Departamento de Engenharia Rural. E-mail: diegoeiras@gmail.com.
}

\footnotetext{
${ }^{2}$ Eng $^{\circ}$. Agrônomo, Orientador e Prof. Ass., Departamento de Engenharia Rural, FCA/UNESP, Rua José Barbosa de Barros, nº 1780. E-mail: biaggioni@fca.unesp.br
} 


\section{INTRODUÇÃO}

O milho é um dos cereais mais cultivados no Brasil e no mundo, em função do valor nutritivo e das produtividades alcançadas.

Vários fatores contribuíram para os ganhos em produtividade da cultura do milho, destacando-se, a maior aplicação de fertilizantes nitrogenados aliada ao aumento na população de plantas e ao melhoramento genético (ARGENTA et al., 2001; DUARTE et al., 2005).

Os produtos agrícolas como o milho, são colhidos após o ponto de maturidade fisiológica, quando os grãos atingem teor de água entre 32 e $38 \%$ e apresentam teores máximos de amido, proteínas e óleo. A colheita na época oportuna, tão logo o grão de milho atinja os teores de água adequados (20 a 24\% para a colheita mecânica e 18 a $22 \%$ para a colheita em espiga), reduz as perdas pelo ataque de roedores, insetos e fungos e diminui os problemas de pós-colheita, pela melhor qualidade do produto e menor grau de infestação. (SARTORI, 2001).

Atualmente, procura-se colher os produtos com teores de água mais elevados, pois existe uma correlação negativa entre as perdas na lavoura e o teor de água, na qual a "secagem na lavoura" acontece com grande perda de matéria seca. As perdas serão menores na medida em que os grãos forem colhidos com mais umidade, permanecendo menos tempo na planta e, portanto, menos sujeito ao ataque de insetos e fungos, que encontram no ambiente quente e úmido, condições ideais para o seu desenvolvimento. O clima favorece, ainda, a respiração que, juntamente com o metabolismo e as reações químicas denominadas oxidação, são as grandes responsáveis pela "quebra", que é a perda de peso dos grãos (FARONI, 1998).

Por outro lado, a colheita antecipada demanda a utilização de sistemas artificiais de secagem, com ar aquecido ou não, que representam uma parte significativa dos custos energético e econômico envolvidos no processo. Ao mesmo tempo, dependendo da época e da região onde o cultivo é conduzido, a secagem não antecipada, processada naturalmente na própria planta ("secagem na lavoura"), poderá proporcionar grãos secos, com um mínimo de perda no peso, além do menor consumo de energia e dinheiro (LEAL, 2012).

Considerando a influência que o teor de matéria seca acumulada nos grãos secos têm sobre os retornos econômico e energético da cultura, o presente trabalho tem por objetivo estudar o efeito de métodos de secagem natural e artificial sobre a perda de matéria seca em grãos de milho, para as condições de Botucatu-SP, bem como ajustar um modelo de regressão para perda de matéria seca dos mesmos durante a secagem na planta.

\section{MATERIAL E MÉTODOS}

O ensaio foi conduzido no ano agrícola 2011/2012, na Fazenda Experimental Lageado, pertencente à Faculdade de Ciências Agronômicas - UNESP, localizada no município de Botucatu - SP, na região centro oeste do Estado de São Paulo, tendo como coordenadas geográficas aproximadas de Latitude $22^{\circ} 51^{\prime} \mathrm{S}$ e Longitude $48^{\circ} 26^{\prime} \mathrm{W}$ de Greenwich, altitude média de $770 \mathrm{~m}$, clima subtropical chuvoso, apresentando inverno seco, tipo Cfa, de acordo com o critério de Köeppen.

Os tratamentos estudados foram: secagem na planta (campo), secagem à sombra com ventilação natural (testemunha), secagem com ar não aquecido e secagem com ar aquecido. Para todos os tratamentos foram determinados no início e ao final: o teor de água pelo método da estufa a $105 \pm 3^{\circ} \mathrm{C}$, peso hectolítrico, massa de mil sementes e peso seco dos grãos. (BRASIL, 2009). A umidade pré-estabelecida para a colheita dos tratamentos de secagem das sementes à sombra com ventilação natural, secagem com ar não aquecido foi de 20,0\%, visando em seguida realizar os tratamentos de secagem artificial; com ar aquecido foi de $25 \%$; e na planta foi deixado continuamente.

Cada tratamento possuía dimensões de $40 \mathrm{~m}$ de comprimento e $51 \mathrm{~m}$ de largura total, comportando 60 linhas de semeadura espaçadas a $0,85 \mathrm{~m}$. Entre cada parcela foi deixado um espaço de $4 \mathrm{~m}$, para a realização das manobras necessárias.

As análises de qualidade seguiram a metodologia pela Regra para análise de sementes (BRASIL, 2009) e foram: teor de umidade pelo método da estufa a $105 \pm 3^{\circ} \mathrm{C}$, por 24 horas e foram utilizados 4 (quatro) repetições e os resultados expressos em porcentagem (base úmida); peso hectolítrico determinado em balança hectolítrica com capacidade de um quarto de litro de sementes para todos os tratamentos com 3 repetições; massa de mil grãos que foi determinado para todos os tratamentos com oito repetições de 100 sementes cada em seguida os grãos de cada repetição são pesados com o número de casas decimais e a partir daí calcula-se: a variância, o desvio padrão e o coeficiente de variação (não exceder 4\%) dos valores obtidos das pesagens. O resultado da determinação é calculado multiplicando-se por 10 o peso médio obtido das repetições de 100 sementes; a perda de matéria seca foi calculada pela equação 1. E a porcentagem da perda da matéria seca é dada pela equação 2 .

$$
\begin{aligned}
& P M S=\left[1-\left(\frac{\% B U}{100}\right)\right] * M m g \\
& \% P M S=\left(\frac{M S_{\text {antes }}-M S_{\text {depois }}}{M S_{\text {antes }}}\right) * 100
\end{aligned}
$$

Onde: PMS = Perda de Matéria Seca $(\mathrm{g}), \% \mathrm{BU}=$ Teor de água da $\operatorname{amostra}(\%), M m g=$ Massa de mil grãos $(\mathrm{g}), \mathrm{MS}_{\text {antes }}=$ MatériaSeca antes, $\mathrm{Ms}_{\mathrm{depois}}=$ MatériaSeca depois

Os resultados obtidos através da secagem foram submetidos à análise de variância. Quando o teste $\mathrm{F}$ mostrou-se significativo a $5 \%$ de probabilidade foi 
aplicado o teste de Tukey para comparação entre as médias a 5\% de probabilidade. E os resultados da análise de qualidade foram transformados em porém são apresentados na tabela são os dados originais. O método de Regressão Linear Múltipla foi utilizado para analisar a correlação existente entre a perda de matéria seca (variável dependente y) com os elementos meteorológicos insolação, pluviometria, velocidade do vento e temperatura (variáveis independentes $\mathrm{x}$ ).

Foi determinado o Coeficiente de Correlação Linear (r), para saber se as variáveis meteorológicas estão significadamente correlacionadas com a perda de matéria seca, ou seja, se é fraca ou forte, e o Coeficiente de Regressão $\left(\mathrm{R}^{2}\right)$, para determinar o grau de explicação que as variáveis meteorológicas explicam a perda em questão, caso essa relação exista. Por fim, utilizou-se o método de regressão múltipla ("enter"), para avaliar a contribuição pura de cada elemento meteorológico no modelo que mais contribuam sobre a perda de matéria seca.

Os dados meteorológicos (Insolação, Pluviometria, Velocidade do Vento, Temperatura) foram obtidos na Estação Agrometeorológica da Fazenda Lageado sob os cuidados do Departamento de Ciências Ambientais da Faculdade de Ciências Agronômicas de Botucatu.

Após obtenção dos dados procedeu-se a análise de variância, e as médias foram comparadas pelo teste de Tukey $(\mathrm{p} \leq 0,05)$.Toda estatística foi feita pelo programa SPSS.

\section{RESULTADOS E DISCUSSÃO}

De acordo com os resultados obtidos, conforme apresentados na Tabela 1, o menor índice de ácidos graxos livres foi encontrado na secagem à sombra (testemunha). Em relação ao teste de condutividade elétrica, não houve diferença significativa entre os sistemas de secagem quando as sementes estavam envolvidas pelo pericarpo.

Tabela 1 - Valores médios do teor de água, do tempo de secagem, das temperaturas do ar ambiente, do ar de secagem e do grão, além da umidade relativa do ambiente obtida durante os processos de secagem.

\begin{tabular}{|c|c|c|c|c|c|c|c|}
\hline & \multicolumn{2}{|c|}{$\begin{array}{c}\text { Teor de água } \\
(\%)\end{array}$} & \multirow{2}{*}{$\begin{array}{c}\text { Temp } \\
\text { o de } \\
\text { Secag } \\
\text { em } \\
\text { em } \\
\text { (h) }\end{array}$} & \multicolumn{2}{|c|}{$\begin{array}{l}\text { Ambiente de } \\
\text { secagem }\end{array}$} & \multicolumn{2}{|c|}{$\begin{array}{c}\text { Ar de secagem } \\
\left({ }^{\circ} \mathrm{C}\right)\end{array}$} \\
\hline & Inicial & Final & & UR\% & $\mathrm{T}^{\circ} \mathrm{C}$ & Plenum & $\begin{array}{c}\text { Massa } \\
\text { do } \\
\text { grão }\end{array}$ \\
\hline $\begin{array}{l}\grave{A} \\
\text { sombra }\end{array}$ & 19,07 & 11,49 & 264 & 71,40 & 19,79 & $\emptyset$ & $\varnothing$ \\
\hline Alta ${ }^{\circ} \mathrm{C}$ & 26,26 & 11,04 & 10 & 80,08 & 24,03 & 58,13 & 41,97 \\
\hline $\begin{array}{l}\mathrm{Ar} \\
\text { natural }\end{array}$ & 19,27 & 11,82 & 144 & 68,12 & 24,25 & 24,83 & 23,41 \\
\hline Planta & 18,54 & 11,75 & 1512 & 79,7 & 18,4 & $\varnothing$ & $\varnothing$ \\
\hline
\end{tabular}

Verifica-se, pela análise da Tabela 1, que, para os tratamentos envolvendo secagem à sombra, com ar natural e na planta, procurou-se trabalhar com teor de água inicial nos grãos entre 18 e $20 \%$, conforme recomendação para os sistemas que empregam a secagem com ar à temperatura ambiente. Para a secagem em alta temperatura, em função da maior velocidade do processo, pôde-se antecipar a colheita iniciando-se a secagem quando os grãos atingiram teor de água inicial próximo de 25\%, aproximando-se, também, do procedimento padrão de secagem de milho em altas temperaturas. Para todos os tratamentos, buscou-se encerrar a secagem quando o teor de água final atingiu cerca de $12 \%$.

Analisando-se, ainda pela Tabela 1, quanto aos tempos de secagem obtidos, observou-se um período relativamente longo para os tratamentos que utilizaram ar ambiente sem convecção forçada, os quais perfizeram tempos de 11 e 63 dias, respectivamente, para secagem à sombra e na planta. Biaggioni (1994), também trabalhando com secagem de milho na planta na região de Botucatu, precisou de apenas 31 dias para reduzir a umidade de $22 \%$ para $13,5 \%$. A diferença de pouco mais de 1 mês entre estes dois trabalhos de secagem na planta pode ser explicada, principalmente, pelas condições do clima de cada época, já que, numa secagem no campo o grão fica sujeito, durante todo o período, às variações de temperatura e umidade relativa do ambiente. Enquanto em Biaggioni (1994) a umidade relativa média registrou $69 \%$ com $18 \mathrm{~mm}$ em média de precipitação, no presente trabalho, estes valores atingiram $79,7 \%$ e $200 \mathrm{~mm}$, aproximadamente.

A secagem com ar natural com temperatura próxima ao ambiente, embora também constituindo-se num sistema que depende do potencial de secagem do ar ambiente, proporcionou um tempo de secagem bem inferior em relação à secagem na planta e à sombra, finalizando após 6 dias de operação (Tabela 1). Este tempo ficou muito próximo daquele obtido por Oliva (2012) que, secando crambe (Crambe abyssinica) no mesmo secador precisou de apenas 5 dias de secagem. Embora a secagem do milho com ar natural tenha se iniciado na mesma época da secagem à sombra e na planta (Tabela 1), a maior rapidez do primeiro pode ser explicada, principalmente, pelo uso da ventilação forçada, permitindo um maior número de ciclos de troca de calor e massa num mesmo período de tempo.

A Tabela 1 mostra, ainda, o tempo de secagem de apenas 10 horas exigido pelo sistema de secagem em alta temperatura. Este valor ficou um pouco acima daquele obtido por Oliva (2012) que, secando sementes de crambe no mesmo protótipo, demandou 6,6 horas. Embora, no presente estudo, tenha-se trabalhado com temperaturas de secagem mais altas, chegando a atingir $63^{\circ} \mathrm{C}$ no ar e $58^{\circ} \mathrm{C}$ na massa de grãos, o maior tempo registrado pode ser explicado pela maior quantidade de água removida em relação ao crambe, que iniciou a secagem com umidade inicial de $16 \%$. 
Os resultados dos testes de qualidade aplicados aos grãos de milho submetidos à secagem na sombra, com ar natural, em alta temperatura e na planta são apresentados na Tabela 2.

\section{Tabela 2 - Resultado do teste de Tukey para os valores médios obtidos nas análises de Perda de Matéria Seca (PMS), Perda de Peso de Mil Grãos (PPMG) e Peso Hectolítrico (PH), segundo os diferentes sistemas de secagem.}

\begin{tabular}{|c|c|c|c|c|c|c|c|c|c|}
\hline \multirow[b]{2}{*}{$\begin{array}{c}\grave{A} \\
\text { sombra }\end{array}$} & \multirow{2}{*}{$\begin{array}{c}\text { PMS\% } \\
2,61 \\
\text { a }\end{array}$} & \multicolumn{2}{|c|}{ I C $95 \%$} & PPMG \% & \multicolumn{2}{|c|}{ I C 95\% } & \multirow{2}{*}{$\begin{array}{c}\text { PH } \\
5,72 \\
b\end{array}$} & \multicolumn{2}{|c|}{$\begin{array}{l}\text { I C } \\
95 \%\end{array}$} \\
\hline & & 1,23 & 2,42 & 9,27 a & 2,72 & 3,44 & & 2,50 & 2,68 \\
\hline $\begin{array}{c}\mathrm{Ar} \\
\text { natural }\end{array}$ & $\begin{array}{c}2,16 \\
\mathrm{a}\end{array}$ & 1,44 & 2,08 & $9,15 \mathrm{a}$ & 2,86 & 3,49 & $\begin{array}{c}6,21 \\
b\end{array}$ & 2,53 & 2,83 \\
\hline $\begin{array}{l}\text { Alta } \\
{ }^{\circ} \mathrm{C}\end{array}$ & $\begin{array}{c}7,81 \\
\mathrm{~b}\end{array}$ & 2,36 & 3,50 & $9,59 \mathrm{ab}$ & 2,90 & 3,58 & $\begin{array}{c}14,10 \\
\mathrm{c}\end{array}$ & 3,68 & 4,08 \\
\hline Planta & $\begin{array}{c}10,40 \\
\text { b }\end{array}$ & 2,84 & 3,85 & $13,12 \mathrm{~b}$ & 3,38 & 4,11 & $\begin{array}{c}4,24 \\
\mathrm{a}\end{array}$ & 2,00 & 2,56 \\
\hline CV\% & 33,21 & & & 11,98 & & & 22,14 & & \\
\hline
\end{tabular}

\section{C.V.: Coeficiente de variação}

Médias seguidas pela mesma letra não diferem entre si pelo teste de Tukey $(p \leq 0,05)$

Analisando-se os dados de variação de matéria seca, verificou-se uma perda proporcionada por todos os sistemas investigados, embora apenas o tratamento "secagem na planta" tenha registrado uma perda significativa, de 10,40\% (Tabela 2) Tal variação, bem superior àquela detectada nos demais tratamentos (Tabela 2), pode ser atribuída ao longo tempo de permanência do grão no campo, expondo-se às intempéries e à ação de pragas e microrganismos, desencadeando-se, possivelmente, reações deteriorativas que refletiram na perda de matéria seca.

Embora, entre os demais tratamentos não se tenha detectado diferenças significativas na variação de matéria seca (Tabela 2), observou-se uma tendência de menor deterioração para os tratamentos que empregaram ar de secagem à temperatura ambiente, cujos valores de perda de matéria seca não chegaram a atingir a metade do valor registrado pelo tratamento que empregou alta temperatura.

Tal desempenho entre os tratamentos de secagem estudados pode ser confirmado, também, pelos dados de Perda de Peso de Mil Grãos (PPMG), conforme apresentado na Tabela 2. Verifica-se uma perda elevada e significativa no peso de mil grãos secos na planta, qualificando este tratamento como o de desempenho menos favorecido também. A análise de PPMG também não apontou diferenças significativas para as variações entre os tratamentos "sombra" (testemunha) e "ar natural", mas conseguiu classificar a perda ocasionada pela secagem em alta temperatura num extrato intermediário, no qual, embora fosse estatisticamente igual aos tratamentos de secagem sem aquecimento, também não diferiu estatisticamente da perda originada durante a secagem na planta.

Os resultados encontrados até aqui corroboram aqueles descritos por Eichelberger e Portella (2003), Ferrari Filho (2010), Torres (2010) e Elias e Oliveira (2009) que, também, apontaram para a maior perda de peso de mil grãos quando se secou em temperaturas elevadas ou quando a colheita foi retardada. Como resultado, criamse tensões internas no grão e supõe-se que estas sejam responsáveis pelas trincas nos grãos, isto porque visualmente no tratamento "alta temperatura" foi observado um maior número de grãos trincados em relação a testemunha.

Corroborando Eichelberger e Portella (2003), o surgimento de trincas durante a secagem em alta temperatura também pode ter sido a causa do menor peso hectolítrico constatado no tratamento "alta temperatura" (Tabela 2) Embora, no presente trabalho, não se tenha analisado a porcentagem de trincas segundo os tratamentos de secagem testados, realizou-se uma avaliação visual, em diafanoscópio, de algumas amostras de grãos secos nos tratamentos em alta temperatura e à sombra (testemunha).

Ainda pela análise da Tabela 2, verificou-se um Peso Hectolítrico (PH) de apenas $69,49 \mathrm{~kg} \mathrm{~L}^{-1}$ no milho seco em alta temperatura, enquanto os demais tratamentos registraram $\mathrm{PH}$ em torno de $74 \mathrm{~kg} \mathrm{~L}^{-1}$. Diferentemente do resultado estatístico sinalizado pelas análises PMS e PPMG, o PH indicou a secagem na planta como tratamento com melhor desempenho, seguido pelos tratamentos "à sombra" e "ar natural" (sem diferenças significativas). Este comportamento pode ser explicado pela homogeneidade das amostras antes das análises, possivelmente, os grãos oriundos da planta seriam maiores que os grãos que compunham as amostras secas à sombra e com ar natural.

Ainda em relação ao peso hectolítrico, verificou-se, um comportamento variável deste índice quando utilizado para diferenciar desempenho de sistemas de secagem. Assim que De Castro et al (2009), trabalhando com híbridos de milho secos com ar à temperatura ambiente, encontraram, confirmando o que foi obtido neste trabalho, valores de $\mathrm{PH}$ muito próximos entre os sistemas de secagem com ar natural e na planta (Tabela 2). Já Elias et al (2009) encontraram redução no PH de trigo em decorrência do atraso na colheita. Sendo o PH um índice que representa o peso volumétrico e, portanto, muito influenciado pelo tamanho e forma dos grãos que compõem a amostra, vale destacar que os resultados encontrados em diferentes pesquisas, muitas vezes contraditórios, podem estar relacionados a diferenças nas amostras (teor de água e posição do grão na espiga, principalmente).

Considerando que todo o milho utilizado no experimento era provenientes de um único campo de produção, homogêneo, pode-se deduzir que a variabilidade detectada entre as amostras iniciais ocorreu devido a uma variabilidade inerente às amostras. Tais variações, 
entretanto, já eram esperadas, pois foram influenciadas pelas perdas de água ocorridas durante o processo de secagem e não necessariamente por uma perda exclusiva de qualidade ocasionada por deterioração. Já no caso da variável perda de matéria seca, na qual se encontra expurgada a variação de peso devido à remoção de água durante a secagem, verificou-se, quebra técnica significativa em todos os tratamentos de secagem, sugerindo um efeito imediato da operação de secagem sobre a qualidade dos grãos.

O teor de água constitui-se no fator mais importante que atua no processo de deterioração dos grãos. A secagem rápida e mantendo-os em níveis de baixa umidade obtêm-se diminuições no ataque de microrganismos e, principalmente, na taxa de respiração dos grãos, com consequente redução da perda de matéria seca (ZOCCOLER, 2005). A taxa de secagem na velocidade em que ocorre a redução de água dos grãos na planta, após atingirem o ponto de maturidade fisiológica, sofre influência das condições climáticas da região. Portanto, para iniciar o ajuste de um modelo para estimar a perda de matéria seca dos grãos que sofreram secagem natural, foi analisada a relação existente entre a taxa de secagem (TS) e as variáveis climáticas: temperatura, umidade relativa, velocidade do vento, insolação e precipitação. $\mathrm{Na}$ secagem natural a taxa de secagem pode ser explicada pela equação 3 .

$$
\mathrm{TS}=\frac{\left[\mathrm{PMG}\left(\% \mathrm{bu}_{\text {inicisa }}-\% \mathrm{bu}_{\text {final }}\right)\right]}{\left[700-\left(7 \times \% \mathrm{bu}_{\text {final }}\right)\right]}
$$

Onde: $\mathrm{TS}=$ taxa de secagem $\left(\mathrm{g} \mathrm{H}_{2} \mathrm{O}\right.$ dia $\left.^{-1}\right) ; \mathrm{PMG}=$ peso de mil grãos $(\mathrm{g}) ; \%$ bu= umidade dos grãos $(\%)$.

A matriz de correlação entre as variáveis na correlação de Pearson é apresentada na Tabela 3.

Tabela 3 - Matriz de correlação entre as variáveis climáticas e taxa de secagem dos grãos na planta na safra verão 2012.

\begin{tabular}{ccccccc}
\hline & T. S. & T & UR & V.V & I & P \\
\hline T.S. & 1 & & & & & \\
T & $0,881^{* *}$ & 1 & & & & \\
UR & $-0,746^{* *}$ & $-0,744^{* *}$ & 1 & & & \\
V.V & $0,364^{\mathrm{ns}}$ & $0,331^{\mathrm{ns}}$ & $-0,591^{*}$ & 1 & & \\
I & $0,607^{*}$ & $0,613^{*}$ & $-0,899^{* *}$ & $0,673^{\mathrm{ns}}$ & 1 & \\
$\mathrm{P}$ & $-0,412^{\mathrm{ns}}$ & $-0,315^{\mathrm{ns}}$ & $0,643^{* *}$ & $-0,553^{\mathrm{ns}}$ & $-0,757^{* *}$ & 1
\end{tabular}

NS: Não significativo ( $(p \leq 0,05) ;{ }^{*}$ Significativo $(p \leq 0,05)$; ${ }^{* *}$ Significativo $(\leq 0,01)$.

Onde: TS: taxa de secagem; T:temperatura; UR: umidade relativa; V.V: velocidade do vento; I: insolação; P: precipitação.

Verificou-se que existe relação significativa entre a taxa de secagem e as variáveis climáticas (Tabela 3). Assim ajustou-se um modelo de regressão para explicar a variação da taxa de secagem em função das variáveis climáticas, gerando-se um resultado para regressão múltipla que proporcionou um $\mathrm{R}^{2}$ igual a 0,812 . Segundo Kennedy (2008), o coeficiente de determinação representa a proporção da variação dependente que é explicada pela variação da variável independente. $\mathrm{O}^{2}$ exercerá esse papel de modo significativo no caso de relações lineares estimadas pelo método dos mínimos quadrados ordinários, porém, se faz necessário observar e interpretar os coeficientes de t e p-valor que permite ou não a exclusão de variáveis. Observando-se os valores, verificou-se que a variável temperatura foi significativa pelo teste t (Tabela 4).

\begin{tabular}{ccc} 
Tabela 4 - Tabela de significância das variáveis \\
climáticas, obtidas por meio da \\
regressão linear múltipla. \\
\hline \multicolumn{3}{c}{ Variáveis Climáticas } \\
t p-valour \\
\hline Temperatura & 3,511 & 0,006 \\
Umidade Relativa & $-0,831$ & 0,426 \\
Velocidade do vento & 0,136 & 0,895 \\
Insolação & $-0,771$ & 0,458 \\
Precipitação & $-0,830$ & 0,426
\end{tabular}

Moreira Junior et al (2010) estudando o controle estatístico do processo na secagem de cerâmicas verificaram que houve correlação forte e positiva entre produção e temperatura, e correlação forte e negativa entre produção e umidade relativa do ar e verificaram que existe correlação significativa somente entre algumas das variáveis em relação à produção. As variáveis temperatura e umidade relativa do ar apresentaram multicolineariedade, justificando o uso somente da variável temperatura no seu novo ajuste com a qual foi gerado a equação 4 a variação da taxa de secagem e nesta análise obteve-se um $\mathrm{R}^{2}$ de 0,777 . Na Tabela 5, são encontrados os coeficientes para o modelo obtido com apenas uma variável (temperatura).

\section{Tabela 5 - Coeficientes do modelo da regressão ajustada que estima a taxa de secagem de milho na planta em função da temperatura, durante a safra verão 2012.}

\begin{tabular}{|c|c|c|c|c|c|c|}
\hline \multicolumn{7}{|c|}{ Coeficientes } \\
\hline & $\beta$ & $\mathrm{t}$ & Sig. & $\mathrm{R}$ & $\mathrm{R}^{2}$ & $\mathrm{R}^{2}$ ajustado \\
\hline Constante & $-6,911$ & $-5,552$ & 0,00 & 0,881 & 0,777 & 0,761 \\
\hline Temperatura & 0,414 & 6,983 & 0,00 & & & \\
\hline
\end{tabular}

Pela Tabela 5 é possível formular a equação (4) a partir dos coeficientes Onde: $Y=$ taxa de secagem; $\beta_{0}=$ constante $; \beta_{1}=$ constante da variável; $X_{1}=$ temperatura.

$$
Y=-6,911+0,414 X_{1}
$$

Além da rapidez com que o grão perde água no campo, o tempo que decorre desde a maturidade fisiológica até a colheita também interfere na quantidade de matéria seca perdida pelo grão, assim quanto mais baixo for seu teor de água na colheita (teor de água final), em função da 
maior exposição às intempéries, maiores serão as perdas de matéria seca. Por outro lado, quanto mais prematuramente o grão é retirado do campo (teor de água final mais alto), menores serão as perdas.

A partir de parâmetros que contemplassem não só os efeitos do clima da região, mas, também, a influência do manejo adotado no processo de secagem na planta, procurou-se ajustar um segundo modelo para estimar a perda de matéria seca (PMS) em função da taxa de secagem (TS) e da umidade final dos grãos (U) e, por isso, foi feita nova correlação entre as variáveis precipitação $(\mathrm{P})$; umidade relativa (UR); velocidade do vento (VV) e insolação (I), excluindo a temperatura e introduzindo a taxa de secagem.A matriz de correlação entre as variáveis na correlação de Pearson é apresentada na Tabela 6.

Tabela 6 - Matriz de correlação da perda matéria seca, com todas as variáveis climáticas (menos temperatura) para a secagem de milho na planta na safra verão 2012.

\begin{tabular}{|c|c|c|c|c|c|c|c|}
\hline & $\% \mathrm{PMS}$ & TS & $\mathrm{U}$ & $\mathrm{P}$ & UR & VV & I \\
\hline$\% \mathrm{PMS}$ & 1 & & & & & & \\
\hline TS & $-0,510^{\mathrm{ns}}$ & 1 & & & & & \\
\hline $\mathrm{U}$ & $\begin{array}{c}- \\
0,970 * *\end{array}$ & $0,555^{\mathrm{ns}}$ & 1 & & & & \\
\hline$P$ & $0,655^{\text {ns }}$ & $-0,212^{\text {ns }}$ & $-0,559^{\mathrm{ns}}$ & 1 & & & \\
\hline UR & $0,737 *$ & $0,773^{*}$ & $-0,671^{\mathrm{ns}}$ & $0,672^{\text {ns }}$ & 1 & & \\
\hline VV & $-0,730^{*}$ & $0,760^{*}$ & $0,781^{*}$ & $-0,582^{\mathrm{ns}}$ & $-0,817 *$ & 1 & \\
\hline I & $-0,645^{\mathrm{ns}}$ & $0,625^{\mathrm{ns}}$ & $0,568^{\mathrm{ns}}$ & $-0,777 *$ & $0,956^{* *}$ & $\begin{array}{c}0,7 \\
52 \\
*\end{array}$ & 1 \\
\hline
\end{tabular}

NS: Não significativo ( $p \leq 0,05)$; *Significativo $(p \leq 0,05)$; **Significativo $(\leq 0,01)$.

Verificou-se relação significativa entre a perda de matéria seca, com as variáveis intrínsecas (umidade dos grãos e taxa de secagem) e as variáveis externas (climáticas) (Tabela 6). Assim, ajustou-se um modelo de regressão para explicar a variação da perda de matéria seca em função destas variáveis internas e externas (Tabela 7).

Pode-se verificar pela análise da Tabela 6 que existe relação significativa entre a perda de matéria seca, com as variáveis intrínsecas (umidade dos grãos e taxa de secagem) e as variáveis externas (climáticas), assim procurou-se ajustar um modelo de regressão que pudesse explicar a variação da perda de matéria seca em função destas variáveis internas e externas. O resumo dos dados da regressão está apresentado na Tabela 7.
Tabela 7 - Coeficientes do modelo da regressão ajustada para a perda de matéria seca de milho na planta incluindo todas as variáveis climáticas (exceto temperatura da safra verão 2012).

\begin{tabular}{ccccccc}
\hline Variáveis & $\mathrm{R}^{2}$ & $\begin{array}{c}\mathrm{R}^{2}- \\
\text { ajusta } \\
\text { do }\end{array}$ & $\beta$ & $\mathrm{t}$ & $\begin{array}{c}\mathrm{p}- \\
\text { valor }\end{array}$ & $\mathrm{VIF}$ \\
\hline $\mathrm{TS}$ & & & 0,449 & 0,758 & 0,698 & 2,907 \\
$\mathrm{U}$ & & & $-1,284$ & $-11,451$ & 0,000 & 1,969 \\
$\mathrm{P}$ & 0,989 & 0,974 & 0,007 & 0,079 & 0,942 & 6,178 \\
$\mathrm{UR}$ & & & 0,303 & 2,024 & 0,136 & 4,904 \\
VV & & & 2,667 & 2,156 & 0,12 & 13,558 \\
$\mathrm{I}$ & & & 0,408 & 0,901 & 0,434 & 32,805 \\
\hline
\end{tabular}

Entretanto, é importante destacar que somente esta análise não é suficiente para corroborar o modelo que está na Tabela de 7 onde é apresentado um breve resumo da regressão e nota-se que possui um $\mathrm{R}^{2}=0,989$ que pode ser considerado alto, pois $98,9 \%$ da perda de matéria seca pode ser explicada pelas variáveis internas e externas. $\mathrm{O}$ teste-t mostrou-se significativo para as variáveis: TS, umidade colheita, UR, velocidade do vento e insolação.

Porém o resultado do VIF (variance inflation factor) quantifica a gravidade da multicolineariedade na análise de regressão múltipla. Uma das consequências da multicolineariedade segundo Gujarati (2006), é que, quando acontece, há uma relação perfeita entre as variáveis explanatórias de um modelo de regressão. Contudo, atualmente, o termo multicolineariedade é usando em um sentido mais amplo, onde as variáveis não estão intercorrelacionadas perfeitamente. Sendo assim, em casos de alta colinearidade, é muito provável que se depare com a medida geral de qualidade do ajustamento, $\mathrm{R}^{2}$, pode ser muito alto e os estimadores de MQO e seus erros-padrão podem ser sensíveis a pequenas alterações nos dados.

Segundo Ferreira (1999), uma colinearidade significativa está presente no modelo se o índice VIF é maior do que 5. Se a condição for maior do que 10 , então a colinearidade presente no modelo é severa (O Valor de VIF que o SPSS gera também é um bom indicador de colinearidade valores superiores também é um bom indicador de colinearidade e valores superiores a 5). Tendo em vista o valor de colinearidade encontrado, chegou-se à conclusão que algumas variáveis deveriam ser excluídas do modelo e também o modelo deveria ser refeito para que o mesmo pudesse ser validado.

Assim sendo, foi feita uma nova regressão que eliminasse os efeitos da multicolineariedade e satisfizesse um modelo que pudesse explicar a perda de matéria seca acumulada em função da umidade, umidade relativa e da taxa de secagem. O resumo dos dados da regressão está apresentado na Tabela 8 . 
Tabela 8 - Resumo da regressão com os seus coeficientes e os valores do teste $t, p$ valor e VIF.

\begin{tabular}{ccccccc}
\hline \multicolumn{7}{c}{ Coeficientes } \\
\hline Variáveis & $\mathrm{R}^{2}$ & $\begin{array}{c}\mathrm{R}^{2}- \\
\text { ajustado }\end{array}$ & $\beta$ & $\mathrm{t}$ & $\begin{array}{c}\mathrm{p}- \\
\text { valor }\end{array}$ & $\mathrm{VIF}$ \\
\hline Constante $^{(0)}$ & & & $14,437^{(0)}$ & 2,707 & 0,042 & $-\mathrm{o}-$ \\
$\mathrm{TS}^{(1)}$ & & & $1,471^{(1)}$ & 2,123 & 0,086 & 2,695 \\
Umidade $^{(2)}$ & 0,983 & 0,973 & $-1,22^{(2)}$ & $-14,741$ & 0,000 & 1,194 \\
UR $^{(3)}$ & & & $0,107^{(3)}$ & 2,019 & 0,10 & 3,003 \\
\hline
\end{tabular}

Onde: $\mathrm{Y}=$ Porcentagem perda acumulada de matéria seca; $\beta_{0}=$ constante; $\beta_{1}=$ coeficiente da primeira variável $X_{1} ; \quad \beta_{2}=$ coeficiente da segunda variável $X_{2} ; \beta_{3}=$ coeficiente da terceira variável $\mathrm{X}_{3} ; \mathrm{X}_{1}=$ variável: taxa de secagem; $X_{2}=$ variável: umidade do grão, na colheita; $\mathrm{X}_{3}=$ variável: umidade relativa $\%$.

Tendo o seguinte modelo que está na equação 5:

$$
\mathrm{Y}=14,437+1,471 \mathrm{X}_{1}-1,22 \mathrm{X}_{2}+0,107 \mathrm{X}_{3}
$$

Com o modelo ajustado realizou-se uma simulação, a partir dos dados experimentais, e os resultados calculados foram comparados com os resultados reais, determinando-se o desvio percentual médio que foi calculado conforme a equação 6 :

$P=\frac{100}{n} \sum_{i}^{n} \frac{\mathrm{I} \Delta P_{e x p}-\Delta P_{c a l c} \mathrm{I}}{\Delta P_{e x p}^{P}}$

Onde: $\mathrm{P}=$ desvio percentual médio, $\% ; \mathrm{n}=$ quantidade de dados experimentais; $\Delta \mathrm{Pexp}=$ valores de perda matéria seca obtida experimentalmente; $\Delta$ Pcalc $=$ valores de perda matéria seca predita pelo modelo.

O resultado da comparação entre as curvas de perda de matéria seca real e calculada é apresentado na Figura 1. O desvio percentual médio obtido foi de $12 \%$ enquanto o desvio máximo chegou atingir $25 \%$, não mostrando um bom ajuste aos dados experimentais. Observa-se, ainda pela análise da Figura 1, a tendência do modelo em superestimar a perda de matéria seca durante, praticamente, todo o período monitorado. Tal comportamento pode ser explicado pelo pequeno número de amostras com que se trabalhou, restringindo-se a apenas uma safra, não se obtendo, portanto, uma representatividade adequada para o bom ajuste da regressão.

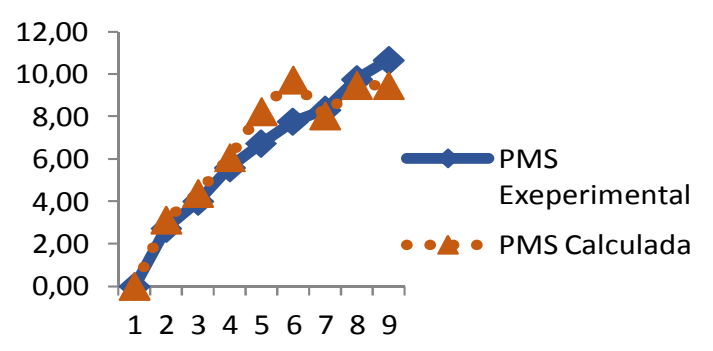

Figura 1 - Comparação entre as curvas de Perda de Matéria Seca (PMS), experimental e calculada, no ano agrícola de 2011/2012, no município de Botucatu.

\section{CONCLUSÃO}

Conclui-se que o sistema de secagem na planta proporcionou, em função do excesso de tempo de permanência do milho no campo, a maior perda de matéria seca e perda de peso de mil grãos; o sistema de secagem em alta temperatura causou em função do elevado número de grãos trincados gerado, a maior redução no peso hectolítrico; o modelo ajustado para estimar a perda de matéria seca dos grãos durante a secagem na planta, para as condições de Botucatu-SP, no ano agrícola 2011/2012, apresentou um $\mathrm{R}^{2}$ de $98,3 \%$ e revelou desvio médio de $12 \%$, apresentando tendência para superestimar a perda de matéria seca.

\section{REFERÊNCIAS}

ARGENTA, G.; SILVA, P. R. F.; SANGOI, L. Arranjo de plantas em milho: análise do estado-da-arte. Ciência Rural, Santa Maria, v. 31, n. 6, p. 1075-1084, 2001.

BIAGGIONI, M. A. M. Análise da secagem de grãos de milho com ar em temperatura próxima a ambiente, para as condições climáticas de BotucatuSP. 1994. 62 f. Dissertação (Mestrado em Engenharia Agrícola)-Universidade Federal de Viçosa, Viçosa, 1994.

BRASIL. Ministério da Agricultura, do Abastecimento e da Reforma Agrária. Secretaria de Defesa Agropecuária. Regras para análise de sementes. Brasília, DF: MAPA, 2009. 365 p.

DE CASTRO M. V. L. et al. Rendimento industrial e composição química de milho de alta qualidade proteica em relação a híbridos comerciais. Pesquisa

Agropecuária Tropical, Goiânia, v. 39, n. 3, p. 233242, jul. /set. 2009.

DUARTE, A. P. et al. Grain quality of Brazilian maize genotypes as influenced by nitrogen level. Crop Science, Madison, v. 45, p. 1958-1964, 2005.

EICHEBERGER L.; PORTELLA, J. A. Secagem de grãos de milho em secador de leito fixo. Pesquisa Agropecuária Gaúcha, Porto Alegre, v. 9, n. 1-2, p. 8591, 2003.

ELIAS, M. C.; OLIVEIRA, M. Aspectos tecnológicos e legais na formação de auditores técnicos do sistema nacional de certificação de unidades armazenadoras. Pelotas: Santa Cruz, 2009. 430 p.

ELIAS, M. C. et al. Umidade de colheita, métodos de secagem e tempo de armazenamento na qualidade tecnológica de grãos de trigo (cv. 'Embrapa 16'). Ciência Rural, Santa Maria, v. 39, n. 1, Fev., 2009. Disponível em: $<$ http://redalyc.uaemex.mx/src/inicio/ArtPdfRed.jsp?iCv 
$\mathrm{e}=33113635005$. ISSN 0103-8478 >. Acesso em: 13 nov. 2012.

FARONI, L. R. D. Fatores que influenciam a qualidade dos grãos armazenados. Revista Iberoamericana de Tecnologia Postcosecha, v. 5, p. 34-41, 1998.

FERRARI FILHO, E. Métodos e temperatura de secagem sobre a qualidade físico-química e microbiológica de grãos de milho no armazenamento. 2010. 95 f. Dissertação (Mestrado em

Fitotecnia/Horticultura)-Universidade Federal do Rio Grande do Sul, Porto Alegre, 2010.

FERREIRA, A. M. SPSS: manual de utilização. Castelo Branco: Escola Superior Agrária, 1999.

GUJARATI, D. Econometria básica. 4. ed. Rio de Janeiro: Elsevier, 2006.

MOREIRA JUNIOR, F. de J. et al. Ajuste de um modelo de previsão de séries temporais para um processo de fabricação de cerâmicas. Revista INGEPRO: Inovação, Gestão e Produção, Santa Maria, v. 2, n. 10, out. 2010.

KENNEDY, P. A Guide to econometrics. Massachusetts: Blackwell Publishing, 2008.

LEAL, P. C. Qualidade de grãos de milho em dietas para frangos. 2012. $99 \mathrm{f}$. Dissertação (Mestrado em Ciências Agrárias)-Universidade Federal do Paraná, 2012.

OLIVA, A. C. E.; BIAGGIONI, M. A. M.;

CAVARIANI, C. Efeito imediato do método de secagem na qualidade de sementes de crambe. Energia na

Agricultura, Botucatu, v. 27, n. 3, p.16-30, 2012.

SARTORI, J. A. Qualidade dos grãos de milho após o processo de secagem. 2001. 54 f. Dissertação (Mestrado em Engenharia Agrícola)-Faculdade de Engenharia Agrícola, Universidade Estadual de Campinas, Campinas, 2001.

TORRES, M. A. P. Desempenho de diferentes métodos de secagem e seus efeitos sobre a qualidade fisiológica de sementes se sorgo granífero. 2010. $122 \mathrm{f}$. Dissertação (Mestrado em Zootecnia)-Pontifícia Universidade Católica, Uruguaiana, 2010.

ZOCCOLER.M.C. Apostila sobre notas de aulas. Ilha Solteira: FEIS-Unesp, 2005. 